\title{
Growth of AlGaSb Compound Semiconductors on GaAs Substrate by Metalorganic Chemical Vapour Deposition
}

\author{
A. H. Ramelan, ${ }^{1}$ H. Harjana, ${ }^{1}$ and P. Arifin ${ }^{2}$ \\ ${ }^{1}$ Physics Department, Research Centre for Smart Materials and Energy, Faculty of Mathematics and Natural Sciences (FMIPA), \\ Sebelas Maret University (UNS), Jl. Ir. Sutami no. 36A, Surakarta 57126, Indonesia \\ ${ }^{2}$ Physics Department, Electronic Materials Laboratory, Faculty of Mathematics and Natural Sciences (FMIPA), \\ Bandung Institute of Technology (ITB), Jl. Ganesha no. 10, Bandung 40132, Indonesia \\ Correspondence should be addressed to A. H. Ramelan, aramelan_uns@yahoo.com
}

Received 14 August 2010; Accepted 1 October 2010

Academic Editor: Maria Antonietta Loi

Copyright (๑) 2010 A. H. Ramelan et al. This is an open access article distributed under the Creative Commons Attribution License, which permits unrestricted use, distribution, and reproduction in any medium, provided the original work is properly cited.

Epitaxial $\mathrm{Al}_{\mathrm{x}} \mathrm{Ga}_{1-\mathrm{x}} \mathrm{Sb}$ layers on $\mathrm{GaAs}$ substrate have been grown by atmospheric pressure metalorganic chemical vapour deposition using TMAl, TMGa, and TMSb. We report the effect of V/III flux ratio and growth temperature on growth rate, surface morphology, electrical properties, and composition analysis. A growth rate activation energy of $0.73 \mathrm{eV}$ was found. For layers grown on GaAs at $580^{\circ} \mathrm{C}$ and $600^{\circ} \mathrm{C}$ with a V/III ratio of 3 a high quality surface morphology is typical, with a mirror-like surface and good composition control. It was found that a suitable growth temperature and V/III flux ratio was beneficial for producing good $\mathrm{AlGaSb}$ layers. Undoped $\mathrm{AlGaSb}$ grown at $580^{\circ} \mathrm{C}$ with a $\mathrm{V} / \mathrm{III}$ flux ratio of 3 at the rate of $3.5 \mu \mathrm{m} /$ hour shows p-type conductivity with smooth surface morphology and its hole mobility and carrier concentration are equal to $237 \mathrm{~cm} / \mathrm{V} . \mathrm{s}$ and $4.6 \times 10^{17} \mathrm{~cm}^{-3}$, respectively, at $77 \mathrm{~K}$. The net hole concentration of unintentionally doped AlGaSb was found to be significantly decreased with the increased of aluminium concentration. All samples investigated show oxide layers $\left(\mathrm{Al}_{2} \mathrm{O}_{3}, \mathrm{Sb}_{2} \mathrm{O}_{3}, \mathrm{and}_{\mathrm{Ga}} \mathrm{O}_{5}\right)$ on their surfaces. In particular the percentage of aluminium-oxide was very high compared with a small percentage of AlSb. Carbon content on the surface was also very high.

\section{Introduction}

Because of the corresponding wavelengths of the alloys of gallium antimonide- (GaSb-) based compound semiconductors cover a wide spectral range from $1.24 \mu \mathrm{m}$ (AlGaSb or $\mathrm{AlGaAsSb}$ ) to $4.3 \mu \mathrm{m}$ (InGaAsSb), they have received increasing attention recently. Consequently, they became promising candidates for applications in long wavelength lasers and photodetectors for fibre optic communication systems [1-3].

It is ideal to grow the AlGaSb films on lattice-matched GaSb substrates. However, due to the lack of semi-insulating GaSb, undoped substrates have a strong free carrier absorption in the mid-IR wavelength region of interest, so that the substrate must be thinned for optimal device operation in the flip-chip mode. For this and commercial reasons, GaAs has been explored as a substrate for $\mathrm{GaSb} / \mathrm{AlGaSb}$ devices. Unfortunately, a lattice mismatch of approximately $7 \%$ exists between GaSb and GaAs. Strain energy can be accommodated by misfit dislocations at the GaAs/GaSb interface. This results in the propagation of threading dislocations through the epilayers [4]. Thus, the growth of undoped high-quality $\mathrm{GaSb} / \mathrm{AlGaSb}$ layers on GaAs substrate becomes a necessary process for preparing thin layers.

These films have usually been grown by liquid phase epitaxy or molecular beam epitaxy (MBE) with relatively little data available for growth of AlGaSb by metalorganic chemical vapor deposition (MOCVD) [5-9]. AlGaSb has proven to be a much more difficult material to grow by MOCVD than GaSb. The simple reason is the reactivity of $\mathrm{Al}$, which forms strong bonds with carbon [6, 7]. It is not surprising then that frequently the MOCVD-grown AlGaSb and $\mathrm{AlSb}$ have been reported to exhibit poor electronic and optical properties. It was also reported by Aardvark et al. [10] that the growth of antimonides by MOVPE is quite different from that for arsenides or phosphides for four 
major reasons: the vapour pressure of antimony over the growing surface, the lack of a stable group $\mathrm{V}$ hydride, the kinetically controlled nature of the growth, and the lack of an insulating antimonide substrate.

In this work, a series of undoped AlGaSb samples were grown on semi-insulating GaAs substrates by MOCVD technique. The growth rates, surface morphology and electrical properties of $\mathrm{AlGaSb}$ were studied as functions of growth temperatures and V/III flux ratio. The elemental microanalysis was also investigated.

\section{Experimental Procedure}

2.1. Growth Conditions. The growth was carried out in a horizontal MOCVD reactor at atmospheric pressure. The precursors were trimethylaluminum (TMAl), trimethylgallium (TMGa), and trimethylantimony (TMSb) held at a temperature of $18^{\circ} \mathrm{C},-9^{\circ} \mathrm{C}$ and $0^{\circ} \mathrm{C}$, respectively. Source materials were diluted in hydrogen to obtain a carrier gas velocity of $1 \mathrm{sccm}$ in the reactor. The substrate was (100) oriented semi-insulating GaAs. GaAs substrates were prepared by degreasing in trichloroethylene (TCE), rinsing in acetone and methanol. The GaAs substrate was etched in a standard solution of $\mathrm{H}_{2} \mathrm{SO}_{4}, \mathrm{H}_{2} \mathrm{O}_{2}$, and $\mathrm{H}_{2} \mathrm{O}(5: 1: 1)$ for $30 \mathrm{~s}$ [11]. The substrates were further rinsed in DI water and rapidly dried under a nitrogen jet.

To minimize oxidation, the substrates were transferred immediately after preparation into a glove box having nitrogen ambient from which they were loaded into the reactor. Before the growth the reactor was evacuated and refilled with hydrogen several times. The GaAs substrate was baked under TMSb partial pressure at a temperature of $640^{\circ} \mathrm{C}$ for 15 minutes to remove the residual oxide film. The growths were performed at temperatures of $580^{\circ} \mathrm{C}$ and $600^{\circ} \mathrm{C}$ measured by a thermocouple located inside the graphite susceptor. The actual temperature of the substrate surface is assumed to be lower due to the cooling effect of the cold carrier gas.

2.2. Characterisation. The surface morphologies of the grown epilayers were observed using Nomarski contrast microscopy. Thicknesses were measured using a Tencor Alpha Step 500 surface profiler. A stylus profiler was routinely employed to record the surface profile of etched AlGaSb samples. The AlGaSb samples deposited on semiinsulating GaAs substrates were characterized by making Van der Pauw structures. Ohmic contacts were formed on the four corners of the square sample using TiAu and/or indium contacts annealed under a nitrogen flow at $250^{\circ} \mathrm{C}$. A CTI closed cycle refrigerator (Model 22C/350C) was used for Hall measurement for the temperature range of $10 \mathrm{~K}-300 \mathrm{~K}$. A VG ESCALAB 220i-XL Analytical XPS system was employed to determine the presence of elements in the samples. Monochromatic AlK $\alpha(1486.6 \mathrm{eV}) \mathrm{X}$-rays flood the sample, the generated photoelectrons are detected by a multidetector concentric hemispherical analyzer (CHA).

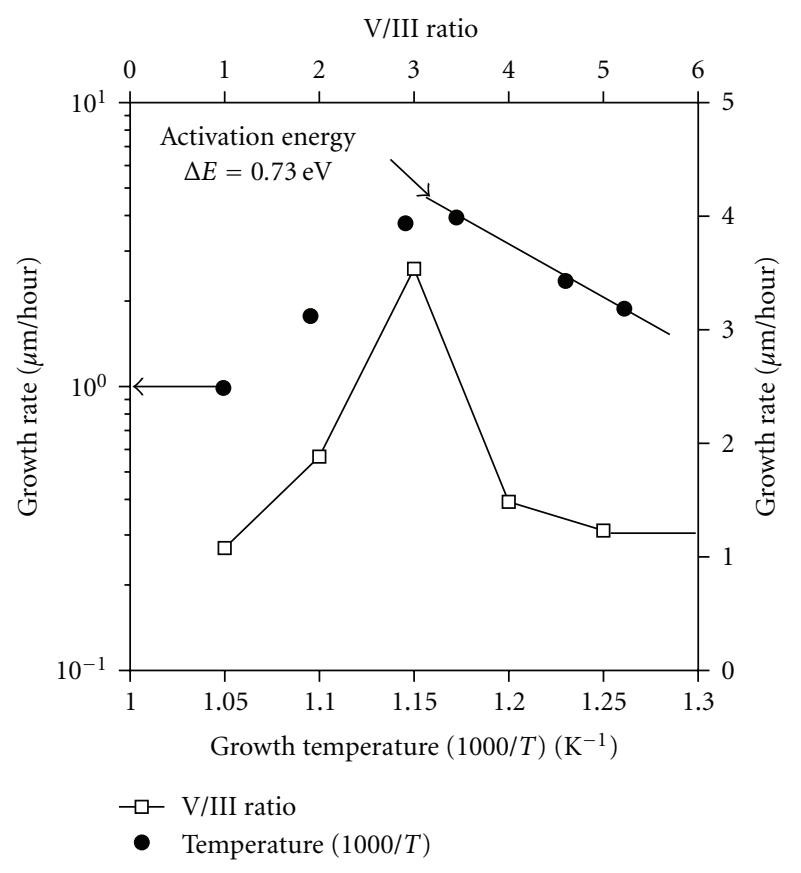

FIGURE 1: Temperature dependence of the $\mathrm{Al}_{0.05} \mathrm{Ga}_{0.95} \mathrm{Sb}$ growth rates and the growth rate of $\mathrm{Al}_{0.05} \mathrm{Ga}_{0.95} \mathrm{Sb}$ epilayers grown at $580^{\circ} \mathrm{C}$ as a function of $\mathrm{V} / \mathrm{III}$ ratio.

\section{Results and Discussion}

3.1. Growth Rate. The two growth parameters that most strongly affect the growth rates are the metalorganic sources partial pressure and the growth temperature. Growth rate is defined as the thickness of the epilayer deposited on a substrate during a certain period of growth. The effect of growth temperature, in the range $520^{\circ} \mathrm{C}-680^{\circ} \mathrm{C}$, on the growth rate was investigated by keeping thers parameters constant. Constant flow rates of $\mathrm{TMAl}=5.6 \mathrm{sccm}, \mathrm{TMGa}=$ $19.1 \mathrm{sccm}$, and $\mathrm{TMSb}=83.6 \mathrm{sccm}$, or equivalent to $\mathrm{V} / \mathrm{III}=3$ were used.

Figure 1 shows the temperature dependence of growth rates for $\mathrm{Al}_{0.05} \mathrm{Ga}_{0.95} \mathrm{Sb}$. In the low temperatures range up to $540^{\circ} \mathrm{C}$, kinetic processes of alkyl decomposition at the substrate surface limit decomposition. This is known as the kinetically controlled regime, where the growth rate depends on temperature (degree of pyrolysis) and very little dependence of growth rate on pressure was observed. A typical exponential relationship between growth rate and growth temperature was observed and the activation energy of $0.73 \mathrm{eV}$ was found. Ungermanns et al. [12] have found an activation energy of $0.80 \mathrm{eV}$ for AlSb growth using dimethylethylaminealane (DMEAAl) as the aluminium source.

The growth rate of $\mathrm{AlGaSb}$ increases monotonically from $540^{\circ} \mathrm{C}$ to $600^{\circ} \mathrm{C}$, while that of arsenic-containing alloys is almost constant in the same temperature range. The difference in behaviour between arsenic and antimonycontaining alloys is explained by taking into account the surface coverage of group V atoms during growth [13]. Sb atoms are excessively absorbed on the growth front because 
of the low vapour pressure. Since $\mathrm{Ga}$ and $\mathrm{Al}$ atoms tend to desorb from the excessively $\mathrm{Sb}$ absorbed surface, only a few $\mathrm{Ga}$ and $\mathrm{Al}$ species can contribute to the growth. This is known as the site-blocking effect. Therefore, a higher growth rate, for Sb-containing alloys, will be obtained for lower $\mathrm{Sb}$ surface coverage condition by selecting higher growth temperatures and/or lower V/III ratio. However, the low surface coverage of $\mathrm{Sb}$ may lead to the formation of $\mathrm{Ga}$ droplets. For higher temperatures, in the range of $580^{\circ} \mathrm{C}$ to $600^{\circ} \mathrm{C}$ the growth rate is constant. This region is a mass transport limited (i.e., the growth rate is controlled predominantly by the concentration of the precursors), because of the complete pyrolysis of the TMGa and TMSb molecules. Further increase in the growth temperatures, leads to a decrease of the growth rate due to desorption of gallium and antimony from the growth surface. The growth rate is not only a function of the availability of atomic species and the rate at which the precursor fragments combine at the surface, but also depends on the carrier gas velocity and the partial pressure of the metalorganic sources [14].

The V/III ratio is another key parameter because both a deficiency and excess of antimony $(\mathrm{Sb})$ on the semiconductor surface lead to a strong degradation of the material quality. Figure 1 shows also the growth rate for the $\mathrm{Al}_{0.05} \mathrm{Ga}_{0.95} \mathrm{Sb}$ films as a function of the V/III ratio. The data indicate that the growth rate is significantly dependent on V/III ratios. At V/III ratios below about 2, the growth rate is low, under $1.87 \mu \mathrm{m} /$ hour. As the V/III ratio increases, the growth rate increases to reach value of $3.54 \mu \mathrm{m} / \mathrm{min}$ near a $\mathrm{V} / \mathrm{III}$ ratio of 3 . In this region, the availability of Sb appears to be the key factor controlling the growth rate. At higher V/III ratios, the growth rate starts to decrease. The strong decrease of the growth rate with increasing TMSb (group $\mathrm{V}$ ) is caused by excess antimony molecules (due to the low vapour pressure of TMSb) at the substrate surface which leads to a decrease to the number of surface sites available for $\mathrm{Al}$ and $\mathrm{Ga}$ adsorptions and a resulting absolute decrease in $\mathrm{Al}$ and $\mathrm{Ga}$ adatoms. This blocking of $\mathrm{Al}$ and $\mathrm{Ga}$ adatoms by excess $\mathrm{Sb}$ results in reduced growth rates. Similar behaviour was reported by Okuno et al. [15] for AlGaSb growth using TMAAl (trimethylaminealane), TMGa and TMSb.

The influence of the alloy composition on the growth rate of $\mathrm{Al}_{\mathrm{X}} \mathrm{Ga}_{1-\mathrm{x}} \mathrm{Sb}$ epilayers was also investigated while keeping the other growth parameters (i.e., temperature, V/III ratio) constant. The result shows the growth rate as a function of alloy composition for two sequences of the $\mathrm{Al}_{\mathrm{x}} \mathrm{Ga}_{1-\mathrm{x}} \mathrm{Sb}$ epilayers grown at $580^{\circ} \mathrm{C}$ and $600^{\circ} \mathrm{C}$. The growth rate does not change significantly over the range of alloy compositions investigated. With respect to good surface morphology and high growth rate, the optimum V/III ratios of 3 for $\mathrm{Al}_{\mathrm{X}} \mathrm{Ga}_{1-\mathrm{x}} \mathrm{Sb}(15 \leq \mathrm{X} \leq 20)$ in the growth temperature range from $580^{\circ} \mathrm{C}$ to $600^{\circ} \mathrm{C}$ have been determined.

3.2. Surface Morphology. Figure 2 shows the surface morphology of selected $\mathrm{Al}_{\mathrm{x}} \mathrm{Ga}_{1-\mathrm{x}} \mathrm{Sb}$ compositions for V/III ratio $=3$ at $580^{\circ} \mathrm{C}$ and $600^{\circ} \mathrm{C}$, respectively. The morphology of $\mathrm{Al}_{\mathrm{x}} \mathrm{Ga}_{1-\mathrm{x}} \mathrm{Sb}$ on GaAs is mirror-like to the naked eye, but the epilayers exhibit microscopic well-defined elongated features. As the $\mathrm{Al}$ content increases, the surface texture changes and the elongated features disappear, to be replaced by featureless texture associated with the highest optical transmission. The interference fringe modulation depths of the epilayers obtained from transmission measurements confirm the high optical quality of the films grown at $580^{\circ} \mathrm{C}$. With further increase of $\mathrm{Al}$ content, several vesselshaped structures appear on the epilayer surface. It has been found for this project that the $\mathrm{Al}_{\mathrm{X}} \mathrm{Ga}_{1-\mathrm{X}} \mathrm{Sb}$ layers grown at $580^{\circ} \mathrm{C}$ and $600^{\circ} \mathrm{C}$ and $\mathrm{V} / \mathrm{III}=3$ with $\mathrm{Al}$ composition in the range of $0.5 \%$ and $30 \%$ are highly regular and accompanied by excellent optical quality, with a very high optical transmission at energies below the bandgap.

3.3. Electrical Properties. For electrical characterisation of the GaSb/AlGaSb layers, semi-insulating GaAs substrates (with lattice mismatch $\Delta a / a$ around $7.5 \%$ ) were used because SI GaSb substrates are not available commercially. The dislocations created by this lattice-mismatch are expected to propagate through the $\mathrm{AlGaSb}$ epilayer, as previously shown for GaInAsSb epilayers grown on SI-GaAs with an $8 \%$ lattice mismatch [16]. However, for our lattice-mismatched layers, the layer thickness may influence the electrical properties, this is due to the reduction of dislocation density with sufficiently thick layers. In fact, Pascal et al. [17] reported that the mobility values for GaSb layers grown on GaAs are only slightly lower than in bulk samples indicating a small influence of the dislocations on the carrier diffusion process. In addition, the variation of the lattice constant for the $\mathrm{Al}_{\mathrm{x}} \mathrm{Ga}_{1-\mathrm{x}} \mathrm{Sb}$ being investigated is relatively small $(\Delta a / a=0.65 \%$ for GaSb/AlSb). Therefore, the electrical measurement of the $\mathrm{Al}_{\mathrm{X}} \mathrm{Ga}_{1-\mathrm{x}} \mathrm{Sb}$ epilayer growns on SI-GaAs may also be relatively unaffected by the lattice mismatch.

Unintentionally undoped AlGaSb is always p-type. The origin of p-type conduction of AlGaSb alloys was often attributed to native lattice defects (i.e., Sb vacancies), antisite defects ( $\mathrm{Ga}$ atoms in Sb sites), and complex defects $\left(\mathrm{V}_{\mathrm{Ga}} \mathrm{Ga}_{\mathrm{Sb}}\right)[18,19]$. Another possible explanation for $\mathrm{p}$ type conduction might be that carbon atoms occupy group$\mathrm{V}$ element sites as acceptor in the materials, as shown by MOVPE-GaAs [20]. The strong $\mathrm{Ga}-\mathrm{C}$ bond forces carbon onto the group- $\mathrm{V}$ sublattice, and therefore carbon is an acceptor. In our studies, we achieved for undoped $\mathrm{Al}_{0.1} \mathrm{Ga}_{0.9} \mathrm{Sb}$ layers (thickness $\sim 3.5 \mu \mathrm{m}$ ) grown under optimum growth conditions, hole concentrations of $4.6 \times$ $10^{17} \mathrm{~cm}^{-3}(77 \mathrm{~K})$, and mobilities of $237 \mathrm{~cm}^{2} /$ V.s $(77 \mathrm{~K})$. Meanwhile, the $\mathrm{Al}_{0.1} \mathrm{Ga}_{0.9} \mathrm{Sb}$ layer grown by Chidley et al. [21] with the same metalorganic sources with our system has a hole concentration of $5 \times 10^{17} \mathrm{~cm}^{-3}(77 \mathrm{~K})$ and mobilities of $232 \mathrm{~cm}^{2} / \mathrm{V} . \mathrm{s}(77 \mathrm{~K})$. As shown in Table 1 , the comparison of the hole concentration and mobility in $\mathrm{Al}_{\mathrm{x}} \mathrm{Ga}_{1-\mathrm{x}} \mathrm{Sb}$ grown by other groups. Therefore, the electrical quality of our $\mathrm{AlGaSb}$ layers is comparable to the best data $\mathrm{AlGaSb}$ films grown by other atmospheric pressure MOVPE. The undoped $\mathrm{GaSb} / \mathrm{AlGaSb}$ with a thickness in the range of $2.3 \mu \mathrm{m}-5.6 \mu \mathrm{m}$ has been grown as well in our MOCVD system, and the hole concentration in the range of $10^{16}-10^{19} \mathrm{~cm}^{-3}$ were measured. This high p-conductivity of AlGaSb is probably 
(i) $x=10 \%$
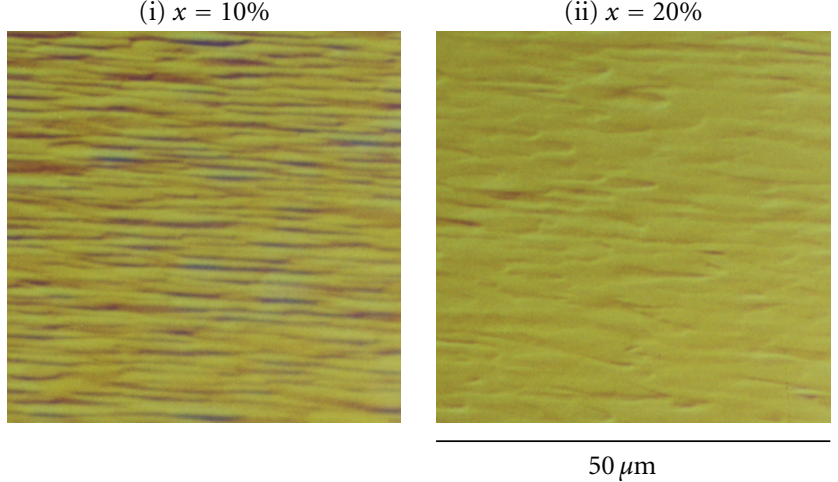

(a) Samples grown at $580^{\circ} \mathrm{C}$

(ii) $x=20 \%$

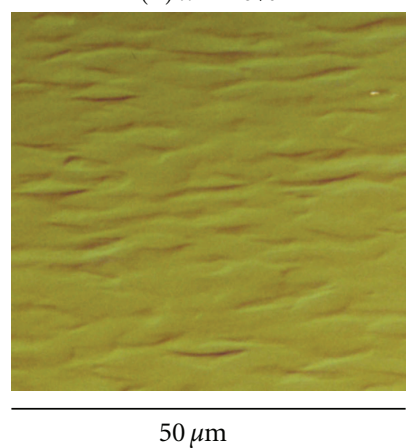

(b) Samples grown at $600^{\circ} \mathrm{C}$ (iii) $x=25 \%$

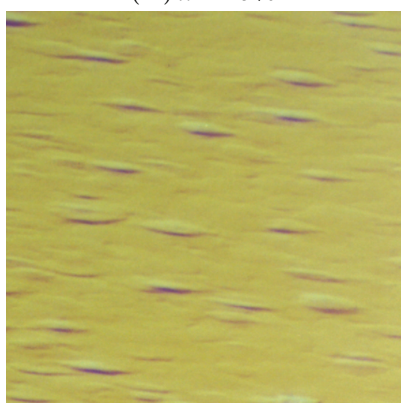

(iii) $x=25 \%$

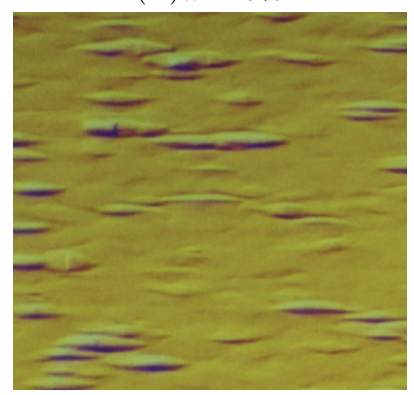

Figure 2: Surface morphology of $\mathrm{Al}_{\mathrm{x}} \mathrm{Ga}_{1-\mathrm{x}} \mathrm{Sb}$ epilayers grown on GaAs with a different Alcontent grown at $580^{\circ} \mathrm{C}$ and $600^{\circ} \mathrm{C}$ with a $\mathrm{V} / \mathrm{III}$ ratio of 3 .

TABLE 1: Hole mobility and carrier concentration of $\mathrm{Al}_{\mathrm{x}} \mathrm{Ga}_{1-\mathrm{x}} \mathrm{Sb}$.

\begin{tabular}{lccccc}
\hline Material & $\operatorname{Tg}\left({ }^{\circ} \mathrm{C}\right)$ & V/III ratio & Mobility $\left(\mathrm{cm}^{2} / \mathrm{V} . \mathrm{s}\right)$ & Concentration $\left(\mathrm{cm}^{-3}\right)$ & Source \\
\hline $\mathrm{Al}_{0.22} \mathrm{Ga}_{0.78} \mathrm{Sb}$ & 600 & 2.0 & $197(300 \mathrm{~K})$ & $1.6 \times 10^{18}$ & Koljonen et al. [10] \\
$\mathrm{Al}_{0.32} \mathrm{Ga}_{0.68} \mathrm{Sb}$ & 650 & 2.5 & $163(300 \mathrm{~K})$ & $5.7 \times 10^{18}$ & Koljonen et al. [10] \\
$\mathrm{Al}_{0.76} \mathrm{Ga}_{0.24} \mathrm{Sb}$ & 650 & 1.5 & $93(300 \mathrm{~K})$ & $2 \times 10^{19}$ & Koljonen et al. $[10]$ \\
$\mathrm{Al}_{0.1} \mathrm{Ga}_{0.9} \mathrm{Sb}$ & 600 & - & $232(77 \mathrm{~K})$ & $5 \times 10^{17}$ & Chidley et al. [21] \\
$\mathrm{Al}_{0.2} \mathrm{Ga}_{0.8} \mathrm{Sb}$ & 600 & - & $97(300 \mathrm{~K})$ & $4.6 \times 10^{19}$ & Chidley et al. [21] \\
$\mathrm{Al}_{0.1} \mathrm{Ga}_{0.9} \mathrm{Sb}$ & 600 & 3 & $176(300 \mathrm{~K})$ & $4.0 \times 10^{18}$ & This work \\
$\mathrm{Al}_{0.2} \mathrm{Ga}_{0.8} \mathrm{Sb}$ & 600 & 3 & $199(300 \mathrm{~K})$ & $2.1 \times 10^{18}$ & This work \\
$\mathrm{Al}_{0.2} \mathrm{Ga}_{0.8} \mathrm{Sb}$ & 580 & 3 & & & This work \\
\hline
\end{tabular}

due to carbon and oxygen incorporation into the layers from the TMAl source.

To investigate the effect of growth temperature on the concentration and mobility, the growth was carried out at temperatures in the range between $520^{\circ} \mathrm{C}$ and $680^{\circ} \mathrm{C}$, keeping TMAl, TMGa, and TMSb constant. As shown in Figure 3, the carrier concentration increases as the growth temperature is increased in the higher growth temperatures from $600^{\circ} \mathrm{C}$ up to $680^{\circ} \mathrm{C}$. However, the rapid increase of carrier concentration in the layer grown at $680^{\circ} \mathrm{C}$ may be partially attributed to the increase in the defect density in the layer, since we also observed the surface degradation of the layer at this temperature. The increased carrier concentration with the growth temperature could also have been caused by increased $\mathrm{Sb}$ vacancies or perhaps by high antisite defect concentrations. Figure 3 shows also the rapid drop in the mobility at this temperature which supports this conclusion. Similar reason in the low temperature region (below $580^{\circ} \mathrm{C}$ ), the carrier concentration increases and simultaneously the mobility declines as the growth temperature decreases. The surface layers degradate as the growth temperatures move away below $580^{\circ} \mathrm{C}$. The surface was covered with antimonide precipitates due to incomplete decomposition of the TMSb. Again, the surface degradation is responsible for decreasing the mobility and increasing the carrier concentration.

Room temperature mobility and carrier concentration for undoped AlGaSb grown at $580^{\circ} \mathrm{C}$ and $600^{\circ} \mathrm{C}$ and $\mathrm{V} / \mathrm{III}$ ratio $=3$ as a function of $\mathrm{Al}$ content are shown in Figure 4. 


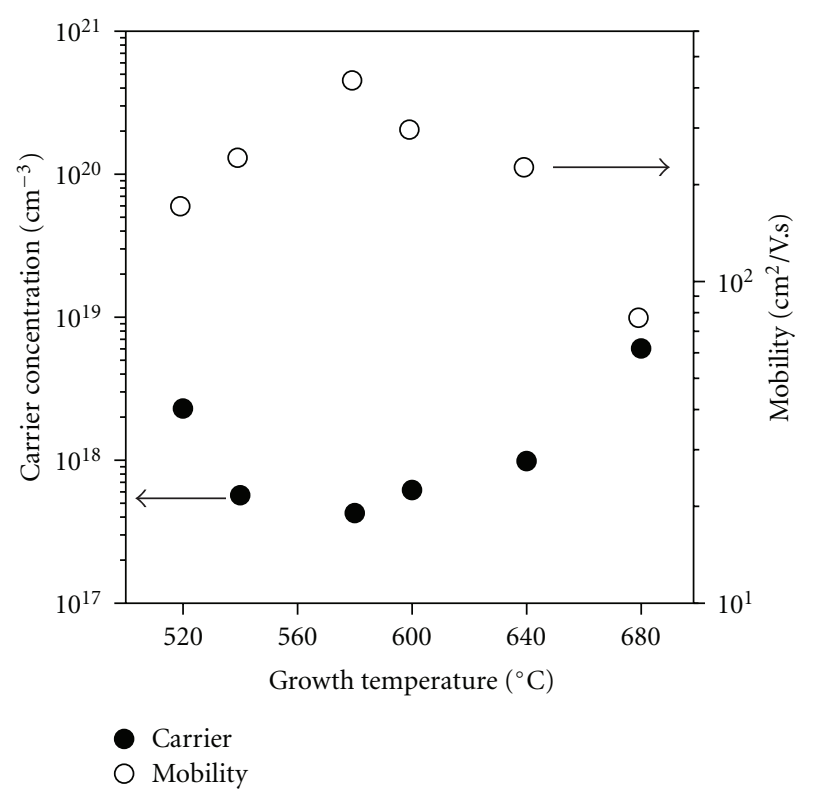

Figure 3: Dependence mobility and carrier concentration at $300 \mathrm{~K}$ on the growth temperature for $\mathrm{Al}_{0.1} \mathrm{Ga}_{0.9} \mathrm{Sb}$ layers grown on $\mathrm{GaAs}$ substrates with a V/III ratio of 3 .

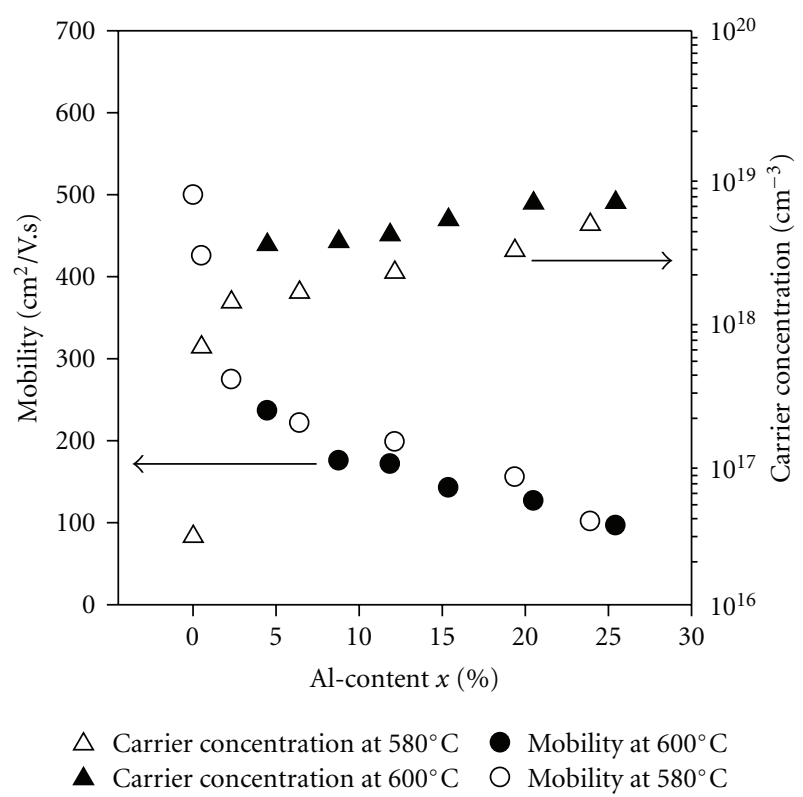

Figure 4: Mobilities and carrier concentration (300 K) for $\mathrm{Al}_{\mathrm{x}} \mathrm{Ga}_{1-\mathrm{x}} \mathrm{Sb}$ layers grown at $580^{\circ} \mathrm{C}$ and $600^{\circ} \mathrm{C}$ as a function of $\mathrm{Al}-$ content (mol-\% AlSb).

When $\mathrm{Al}$ is incorporated into $\mathrm{GaSb}$ in small quantities of $0<x<0.025$, the mobility decreases and the carrier concentration increases sharply. Since the GaSb antisite defect is presumed responsible for the acceptors in GaSb, it is suggested that $\mathrm{Al}$ more readily occupies $\mathrm{V}_{\mathrm{Sb}}$ sites and the incorporation of carbon is enhanced by introducing $\mathrm{Al}$ into GaSb growth, this increases the acceptor concentration.

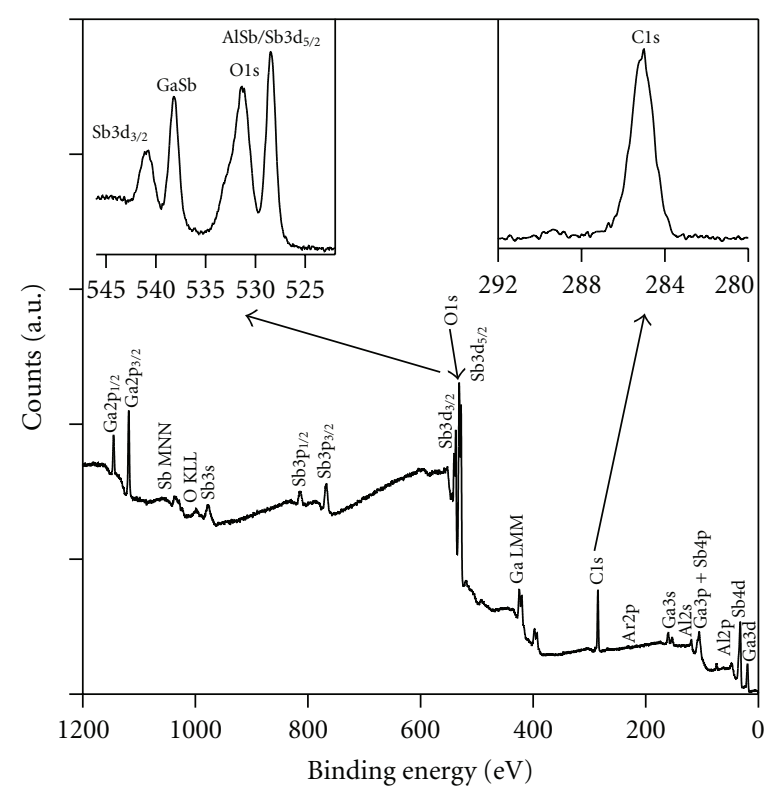

FIGURE 5: XPS wide scan obtained at the surface of $\mathrm{Al}_{0.05} \mathrm{Ga}_{0.95} \mathrm{Sb}$ grown at $600^{\circ} \mathrm{C}$ with a $\mathrm{V} / \mathrm{III}$ ratio of 3 .

A similar sharp increase of carrier concentration by the incorporation of even a small amount of aluminium had been previously reported by Chidley et al. [21] and is attributed to carbon contamination in the MOCVD growth. The RT mobilities for the growth temperature of $580^{\circ} \mathrm{C}$ and $600^{\circ} \mathrm{C}$ are very similar, but the carrier concentration is higher for layers grown at $600^{\circ} \mathrm{C}$.

3.4. Elemental Microanalysis. Two main problems in the application of metalorganic $\mathrm{Al}$ sources have been identified. Firstly, the aluminum-carbon bond in the precursor is very stable leading to an increase carbon contamination. Secondly, because of the high affinity of aluminum to oxygen, metalorganic organic aluminium sources react with $\mathrm{O}_{2}$ and form partially oxidized compounds, which often have a higher vapour pressure than their nonoxidized counterparts. Oxygen then incorporates into the material where it tends to form a deep level impurity in such compounds as $\mathrm{AlGaSb}$ [11]. Certainly, this unintentional impurity incorporation has a negative influence on the electrical and optical properties of the material. The $\mathrm{O}$ and $\mathrm{C}$ contents in our MOCVD-grown films were examined.

Figure 5 is an XPS wide scan spectrum of $\mathrm{Al}_{0.05} \mathrm{Ga}_{0.95} \mathrm{Sb}$ grown on a GaSb substrate at $600^{\circ} \mathrm{C}$ with a V/III ratio of 3 . At the premilled surface, the spectrum indicates the presence of aluminum, gallium, and antimony from the AlGaSb film, and oxygen and carbon due to environmental exposure and metalorganic precursors. The spectrum shows that $\mathrm{O} 1 \mathrm{~s}$ and $\mathrm{O} 2 \mathrm{~s}$ are located at $531 \mathrm{eV}$ and $23 \mathrm{eV}$, respectively. Carbon (C1s) contamination is very high at the surface (before argon ion milling). From the analysis of XPS data, carbon contamination reaches $45.7 \%$ (see inset Figure 5), and oxygen content on the epilayer surface is around $19.6 \%$. 


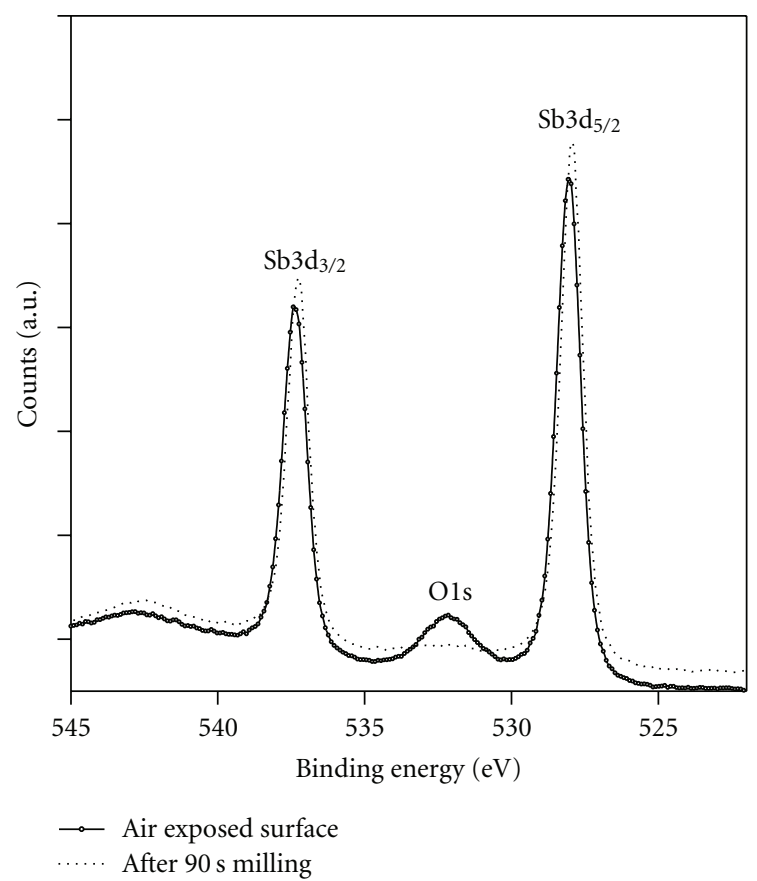

FIgURE 6: XPS narrow scan of $\mathrm{Sb}_{3} \mathrm{~d}_{3 / 2}$ and $\mathrm{Sb}_{3} \mathrm{~d}_{5 / 2}$ at the (a) premilled and (b) 90 second milled surface of $\mathrm{Al}_{0.05} \mathrm{Ga}_{0.95} \mathrm{Sb}$ grown at $600^{\circ} \mathrm{C}$ with a $\mathrm{V} / \mathrm{III}$ ratio of 3 .

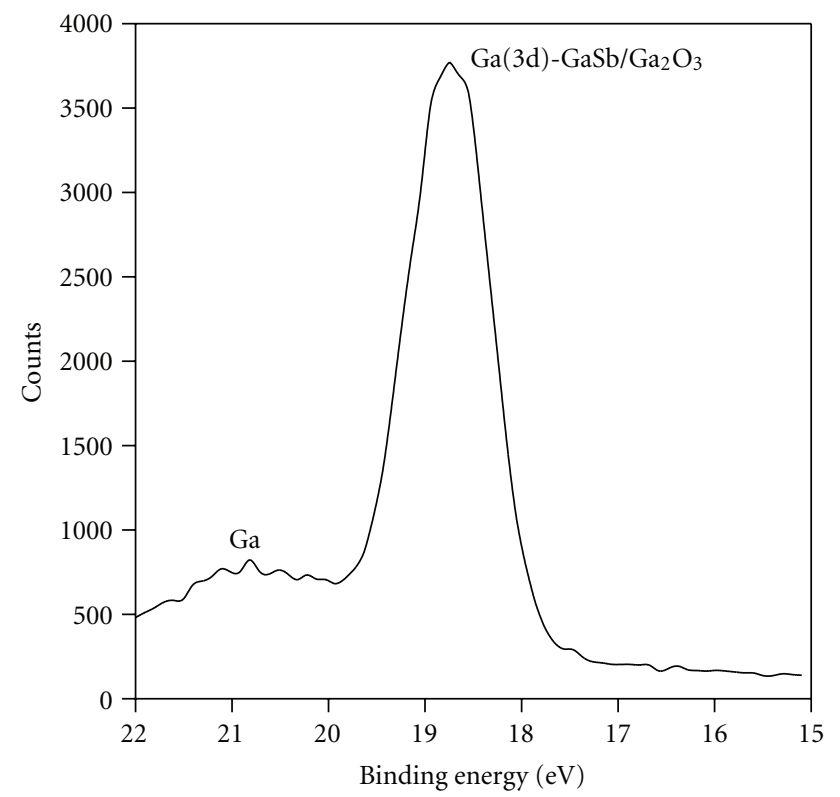

FIGURE 7: XPS narrow scan of Ga3d at the as-received surface of $\mathrm{Al}_{0.05} \mathrm{Ga}_{0.95} \mathrm{Sb}$ grown at $600^{\circ} \mathrm{C}$ with a $\mathrm{V} / \mathrm{III}$ ratio of 3 .

Figure 6 shows XPS narrow scan spectra of the $\mathrm{Sb}_{3} \mathrm{~d}_{3 / 2}$ and $\mathrm{Sb}_{3} \mathrm{~d}_{5 / 2}$ peaks at the premilled and the 90 second milled surfaces of $\mathrm{Al}_{0.05} \mathrm{Ga}_{0.95} \mathrm{Sb}$ layer grown on GaAs grown at $600^{\circ} \mathrm{C}$ with a $\mathrm{V} / \mathrm{III}$ ratio of 3 . For the premilled surface, there are three peaks. The $\mathrm{Sb}_{3} \mathrm{~d}_{3 / 2}$ peak is located at $537.43 \mathrm{eV}$ with a full width at half maximum (FWHM) of $1.01 \mathrm{eV}$, the $\mathrm{Sb}_{3} \mathrm{~d}_{5 / 2}$ peak is at $528.07 \mathrm{eV}$ with a FWHM of $1.06 \mathrm{eV}$, and

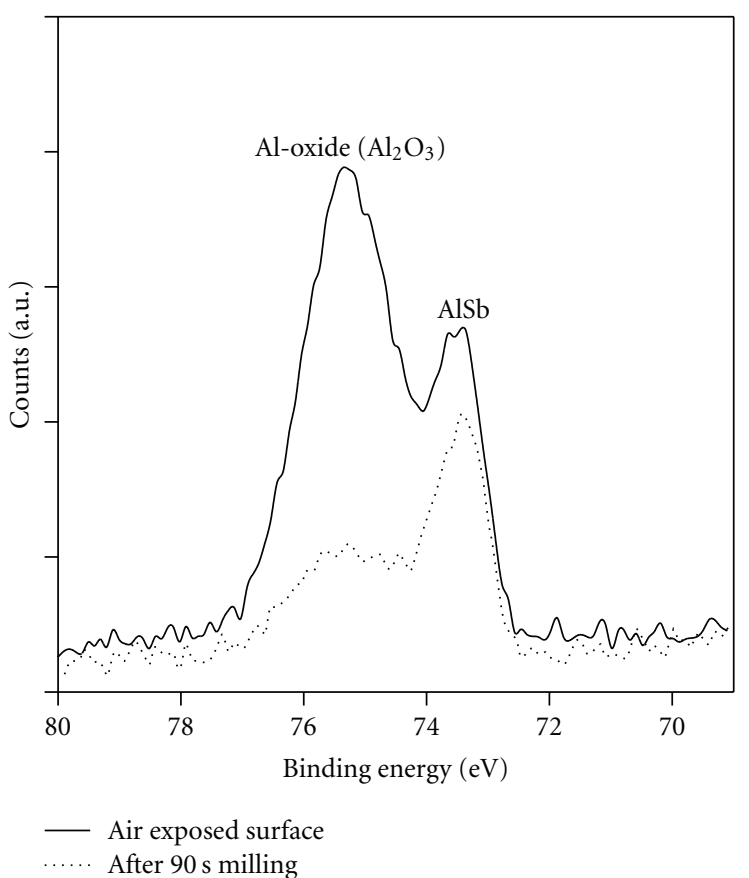

Figure 8: XPS narrow scan of $\mathrm{Al}(2 \mathrm{p}$ ) region (a) premilled and (b) 90 second milling surface of $\mathrm{Al}_{0.05} \mathrm{Ga}_{0.95}$ Sb grown at $600^{\circ} \mathrm{C}$ with a V/III ratio of 3 .

the other peak in between the $\mathrm{Sb}_{3} \mathrm{~d}_{3 / 2}$ and $\mathrm{Sb} 3 \mathrm{~d}_{5 / 2}$ peaks is the $\mathrm{O} 1 \mathrm{~s}$ peak located at $532.15 \mathrm{eV}$. When the sample was milled for 90 seconds, the O1s peak disappear for the layer. This is not surprising since the oxide layer is milled away. The disappearance of O1s causes an increase in intensity for the $S b 3 d_{3 / 2}$ and $S b 3 d_{5 / 2}$ peaks and both peaks shift to lower energies.

For gallium, it is difficult to distinguish whether it exists as $\mathrm{Ga}_{2} \mathrm{O}_{3}$ or $\mathrm{GaSb}$, as the chemical shift between these two states is negligibly small [22]. However, most of the antimony exists in the form of $\mathrm{Sb}_{2} \mathrm{O}_{5}$ at the outermost surface and that gallium tends to react easily with oxygen upon exposure to atmosphere, it can be reasonably deduced that gallium is present mainly in the form of $\mathrm{Ga}_{2} \mathrm{O}_{3}$ at the original surface. Figure 7 shows the Ga 3d region XPS narrow scan of the premilled surface $\mathrm{AlGaSb}$ grown at $580^{\circ} \mathrm{C}$. There are two peaks located at $18.9 \mathrm{eV}$ and $20.8 \mathrm{eV}$, corresponding to $\mathrm{GaSb} / \mathrm{Ga}_{2} \mathrm{O}_{3}$ and elemental gallium, respectively. From the area ratio, it is evident that at the near surface region gallium exists mainly in the forms of $\mathrm{GaSb}$ and $\mathrm{Ga}_{2} \mathrm{O}_{3}$, with a small percentage of elemental gallium.

Figure 8 shows the XPS $\mathrm{Al}(2 \mathrm{p})$ spectra obtained from a $\mathrm{Al}_{0.05} \mathrm{Ga}_{0.95} \mathrm{Sb}$ surface before and after 90 seconds of argon ion milling. For the premilled surface, the $\mathrm{Al}_{2} \mathrm{O}_{3}$ exhibits a high intensity compared to that of the AlSb peak. The ratio of the area shows that at the surface region aluminium exists mainly in the forms of $\mathrm{Al}_{2} \mathrm{O}_{3}$, with a small percentage of AlSb. This occurs because aluminium is very reactive to oxygen. After 90 seconds of milling, a drastic reduction of the $\mathrm{Al}_{2} \mathrm{O}_{3}$ peak intensity was observed relatively to the $\mathrm{AlSb}$ peak as shown in Figure 8. This provides an evidence that the $\mathrm{Al}_{2} \mathrm{O}_{3}$ is a natural oxide layer. 


\section{Conclusions}

A range of $\mathrm{Al}_{\mathrm{x}} \mathrm{Ga}_{1-\mathrm{x}} \mathrm{Sb}$ has been grown by MOCVD with the Al composition in the range $0 \leq x \leq 0.30$ with mirrorlike surface morphology and good composition control. We have found that the $\mathrm{Al}_{\mathrm{x}} \mathrm{Ga}_{1-\mathrm{x}} \mathrm{Sb}$ layers grown at $580^{\circ} \mathrm{C}$ and $600^{\circ} \mathrm{C}$ and at a V/III ratio of 3 with $\mathrm{Al}$ composition in the range of $0.5 \%$ and $25 \%$ have excellent optical quality with a very high optical transmission at energies below the bandgap. In the low temperature range up to $580^{\circ} \mathrm{C}$, the growth rate depends on temperature (degree of pyrolysis of precursors), and the growth rate of AlGaSb increases monotonically. At high temperatures in the range between $580^{\circ} \mathrm{C}$ and $600^{\circ} \mathrm{C}$, the growth rate is constant. Further increasing the growth temperature leads to a decrease of the growth rate due to desorption of gallium and antimony from the growth surface. A growth rate activation energy of $0.73 \mathrm{eV}$ was found. The carrier concentration increases as the growth temperature is increased in the higher growth temperatures from $600^{\circ} \mathrm{C}$ up to $680^{\circ} \mathrm{C}$. The rapid increase of carrier concentration in the layer grown at $680^{\circ} \mathrm{C}$ may be partially attributed to the increase in the defect density in the layer. The carrier concentration increases and mobility decreases very rapidly as the $\mathrm{Al}$ is introduced in small quantities of $0<x<0.025$ into the composition. This is thought to be due to AlSb antisite defect and carbon contamination. Further degradation of electrical properties with $\mathrm{Al}$ incorporation is not that pronounced. The RT mobility is in the order of $100-426 \mathrm{~cm} 2 /$ V.s and carrier concentration $6.27 \times 10^{17}-4.48$ $\times 10^{18} \mathrm{~cm}^{-3}$ for compositions in the range of $0.025<x<$ 0.25 . All the samples investigated showed oxide layers $\left(\mathrm{Al}_{2} \mathrm{O}_{3}\right.$, $\mathrm{Sb}_{2} \mathrm{O}_{3}$, and $\left.\mathrm{Ga}_{2} \mathrm{O}_{5}\right)$ on the surface layers, the percentage of aluminium-oxide is especially high compared with a small percentage of AlSb. This indicates that aluminium is very reactive to oxygen from the environment. XPS analysis reveals that carbon and oxygen contents on the surface layers mainly originated from atmosphere exposure.

\section{Acknowledgments}

The financial support from the Directorate General of Higher Education (DIKTI), the Ministry of National Education (DIKNAS), and the Government of the Indonesia Republic is gratefully acknowledged.

\section{References}

[1] S. M. Kluth, J. D. Fitz Gerald, and M. C. Ridgway, "Ionirradiation-induced porosity in GaSb," Applied Physics Letters, vol. 86, no. 13, Article ID 131920, 3 pages, 2005.

[2] H. Shao, W. Li, A. Torfi, D. Moscicka, and W. I. Wang, "Roomtemperature InAsSb photovoltaic detectors for mid-infrared applications," IEEE Photonics Technology Letters, vol. 18, no. 16, pp. 1756-1758, 2006.

[3] Y. H. Kim, J. Y. Lee, Y. G. Noh, M. D. Kim, and J. E. Oh, "High-resolution transmission electron microscopy study on the growth modes of GaSb islands grown on a semi-insulating GaAs (001) substrate," Applied Physics Letters, vol. 90, no. 24, Article ID 241915, 3 pages, 2007.
[4] R. Hao, Y. Xu, Z. Zhou et al., "Growth of GaSb layers on GaAs ( $\left.\begin{array}{lll}0 & 0 & 1\end{array}\right)$ substrate by molecular beam epitaxy," Journal of Physics D, vol. 40, no. 4, pp. 1080-1084, 2007.

[5] P.-Y. Wang, J. F. Chen, and W. K. Chen, "Structural and electrical properties of $\mathrm{GaSb}, \mathrm{AlGaSb}$ and their heterostructures grown on GaAs by metalorganic chemical vapor deposition," Journal of Crystal Growth, vol. 160, no. 3-4, pp. 241-249, 1996.

[6] Y. C. Lin, H. Yamaguchi, E. Y. Chang et al., "Growth of veryhigh-mobility AlGaSb/InAs high-electron-mobility transistor structure on si substrate for high speed electronic applications," Applied Physics Letters, vol. 90, no. 2, Article ID 023509, 3 pages, 2007.

[7] C. A. Wang, "Organometallic vapor phase epitaxial growth of AlSb-based alloys," Journal of Crystal Growth, vol. 170, no. 1-4, pp. 725-731, 1997.

[8] S. K. Haywood, R. W. Martin, N. J. Mason, R. J. Nicholas, and P. J. Walker, "GaSb/InAs heterojunctions grown by MOVPE," Journal of Crystal Growth, vol. 107, no. 1-4, pp. 422-427, 1991.

[9] F. S. Juang, Y. K. Su, N. Y. Li, and K. J. Gan, "Effects of trimethylantimonide/triethylgallium ratios on epilayer properties of gallium antimonide grown by low-pressure metalorganic chemical vapor deposition," Journal of Applied Physics, vol. 68, no. 12, pp. 6383-6387, 1990.

[10] A. Aardvark, N. J. Mason, and P. J. Walker, "The growth of antimonides by MOVPE," Progress in Crystal Growth and Characterization of Materials, vol. 35, no. 2-4, pp. 207-241, 1997.

[11] T. Koljonen, M. Sopanen, H. Lipsanen, and T. Tuomi, "Metalorganic vapor phase epitaxial growth of AlGaSb and AlGaAsSb using all-organometallic sources," Journal of Crystal Growth, vol. 169, no. 3, pp. 417-423, 1996.

[12] Ch. Ungermanns, H. Hardtdegen, M. Matt et al., "MOMBE and characterization of InAs and (Al,Ga)Sb," Journal of Crystal Growth, vol. 188, no. 1-4, pp. 32-38, 1998.

[13] H. Asahi, T. Kaneko, Y. Okuno, and S. Gonda, "Improved growth kinetic model for metalorganic molecular beam epitaxy using triethylgallium," Japanese Journal of Applied Physics, Part 1, vol. 32, no. 6, pp. 2786-2793, 1993.

[14] T. Koljonen, M. Sopanen, H. Lipsanen, and T. Tuomi, "Growth of high-quality GaSb by metalorganic vapor phase epitaxy," Journal of Electronic Materials, vol. 24, no. 11, pp. 1691-1696, 1995.

[15] Y. Okuno, H. Asahi, T. Kaneko, Y. Itani, K. Asami, and S. Gonda, "MOMBE growth of AlGaSb," Journal of Crystal Growth, vol. 115, no. 1-4, pp. 236-240, 1991.

[16] J. M. Kang, M. Nouaoura, L. Lassabatère, and A. Rocher, "Accommodation of lattice mismatch and threading of dislocations in GaSb films grown at different temperatures on GaAs (001)," Journal of Crystal Growth, vol. 143, no. 3-4, pp. 115123, 1994.

[17] F. Pascal, F. Delannoy, J. Bougnot et al., "Growth and characterization of undoped and N-type (Te) doped MOVPE grown gallium antimonide," Journal of Electronic Materials, vol. 19, no. 2, pp. 187-195, 1990.

[18] S. C. Chen and Y. K. Su, "Photoluminescence study of gallium antimonide grown by liquid-phase epitaxy," Journal of Applied Physics, vol. 66, no. 1, pp. 350-353, 1989.

[19] M.-C. Wu, C.-W. Chen, and C.-C. Chen, "Growth-temperature dependence of electrical and luminescent properties of high-quality GaSb grown by liquid-phase epitaxy," Journal of Applied Physics, vol. 72, no. 3, pp. 1101-1103, 1992.

[20] G. B. Stringfellow, Organometalic Vapor-Phase Epitaxy, Academic Press, San Diego, Calif, USA, 1989. 
[21] E. T. R. Chidley, S. K. Haywood, R. E. Mallard et al., "GaSb heterostructures grown by MOVPE," Journal of Crystal Growth, vol. 93, no. 1-4, pp. 70-78, 1988.

[22] J. F. Moulder, W. F. Stickle, P. E. Sobol, and K. D. Bomben, A Handbook of X-Ray Photoelectron Spectroscopy, Physical Electronics Division, Perkin-Elmer Corporation, Eden Prairie, Minn, USA, 1992. 

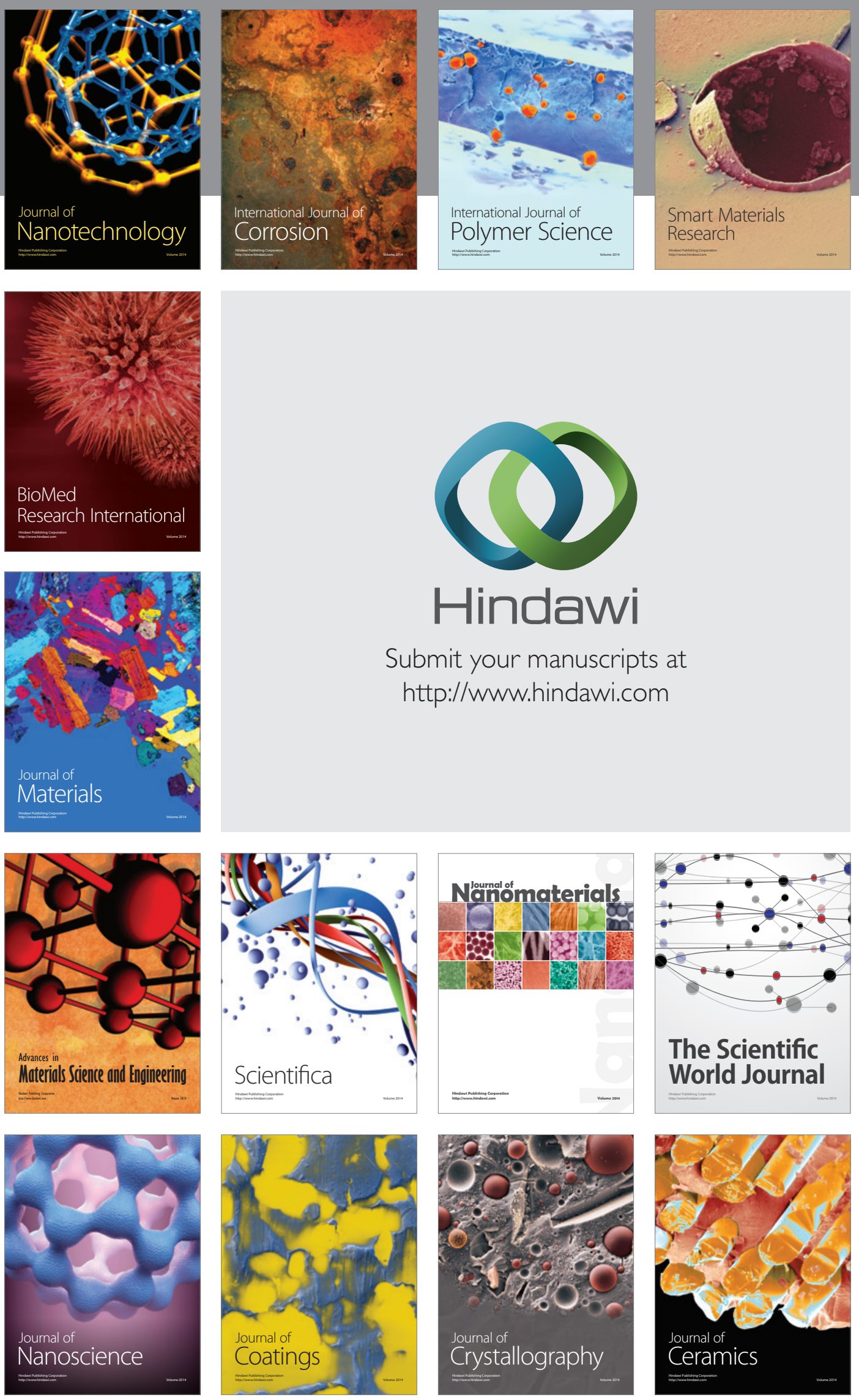

The Scientific World Journal

Submit your manuscripts at

http://www.hindawi.com

\section{World Journal}

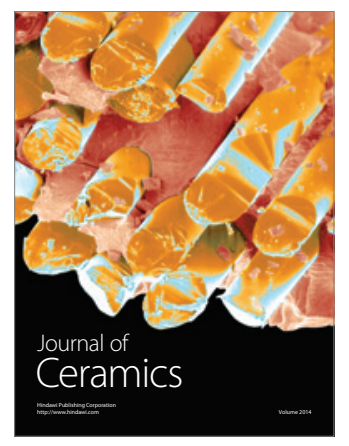

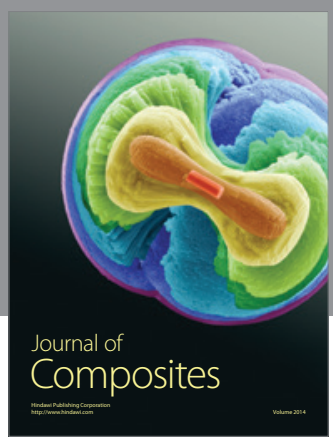
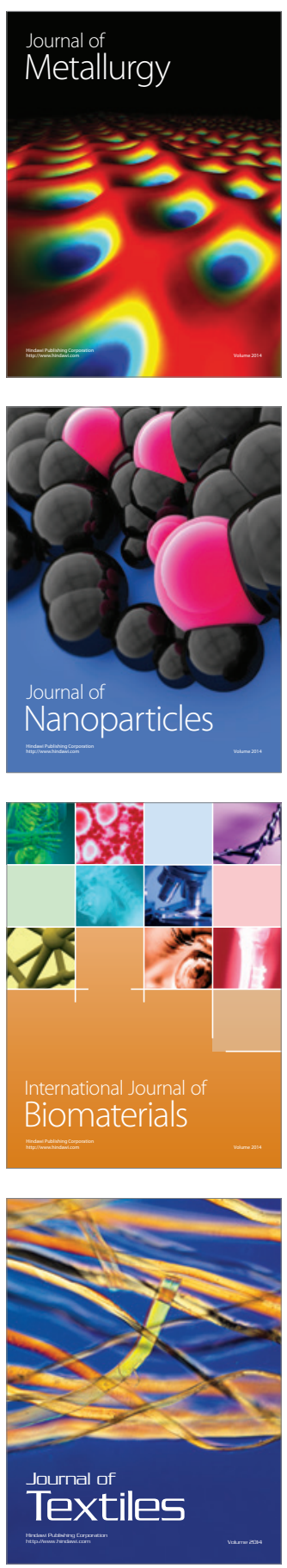